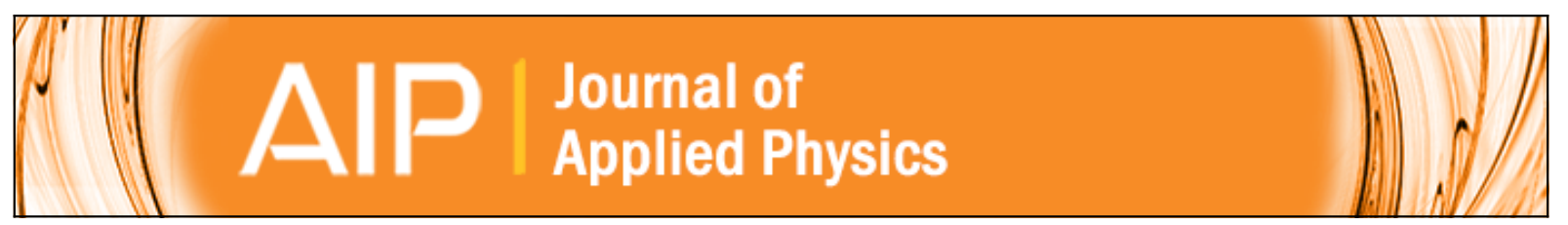

\title{
Elucidation on Joule heating and its consequences on the performance of organic light emitting diodes
}

Priyanka Tyagi, Lalat Indu Giri, Suneet Tuli, and Ritu Srivastava

Citation: Journal of Applied Physics 115, 034518 (2014); doi: 10.1063/1.4861412

View online: http://dx.doi.org/10.1063/1.4861412

View Table of Contents: http://scitation.aip.org/content/aip/journal/jap/115/3?ver=pdfcov

Published by the AIP Publishing

\section{Articles you may be interested in}

Barrier performance optimization of atomic layer deposited diffusion barriers for organic light emitting diodes using x-ray reflectivity investigations

Appl. Phys. Lett. 103, 233302 (2013); 10.1063/1.4839455

Substrate thermal conductivity effect on heat dissipation and lifetime improvement of organic light-emitting diodes Appl. Phys. Lett. 94, 253302 (2009); 10.1063/1.3154557

Effect of transparent film desiccant on the lifetime of top-emitting active matrix organic light emitting diodes Appl. Phys. Lett. 90, 103518 (2007); 10.1063/1.2712776

Impact of Joule heating on the brightness homogeneity of organic light emitting devices

Appl. Phys. Lett. 90, 103506 (2007); 10.1063/1.2711708

Imaging Joule heating in a conjugated-polymer light-emitting diode using a scanning thermal microscope Appl. Phys. Lett. 84, 4890 (2004); 10.1063/1.1762988

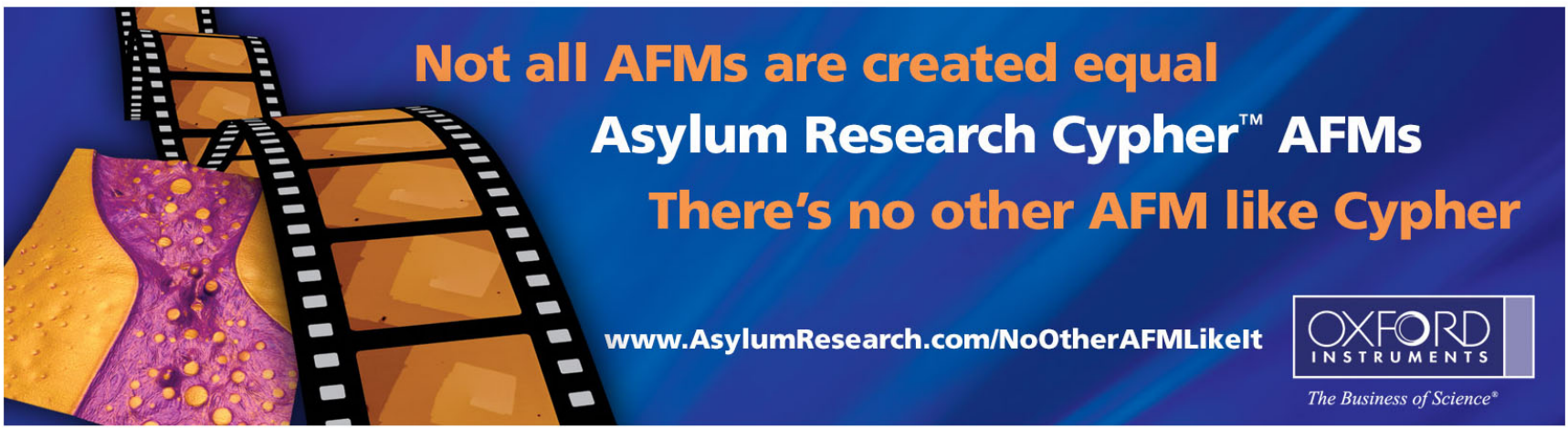




\title{
Elucidation on Joule heating and its consequences on the performance of organic light emitting diodes
}

\author{
Priyanka Tyagi, ${ }^{1,2, a)}$ Lalat Indu Giri, ${ }^{2}$ Suneet Tuli, ${ }^{2}$ and Ritu Srivastava ${ }^{1, b)}$ \\ ${ }^{1}$ CSIR-Network of Institute for Solar Energy (NISE), Physics of Energy Harvesting Division, \\ CSIR-National Physical Laboratory, Dr. K. S. Krishnan Road, New Delhi-110012, India \\ ${ }^{2}$ Center for Applied Research in Electronics, Indian Institute of Technology Delhi, New Delhi-110016, India
}

(Received 7 October 2013; accepted 20 December 2013; published online 21 January 2014)

\begin{abstract}
Current work presents a quantitative analysis of Joule heating by temperature measurements using infrared thermography and heat estimation of organic light emitting diodes (OLEDs) and their correlation with device life time. These temperature measurements were performed at 10, 20, 30, 40 , and $50 \mathrm{~mA} / \mathrm{cm}^{2}$ current densities and studied with operational time. The temperature rise of the device has increased from 9.8 to $16.6^{\circ} \mathrm{C}$ within $168 \mathrm{~h}$ at an operating current density of $40 \mathrm{~mA} / \mathrm{cm}^{2}$. This has been ascribed as due to the external contamination by water, oxygen, and dust particles as well as by internal heat generation. Encapsulation of the device avoids external degradation of OLEDs by preventing the destruction caused by these external contaminations. In this way, encapsulation has led to the decreased temperature rise of $12.4^{\circ} \mathrm{C}$ within the duration of $168 \mathrm{~h}$, which reflects the improved stability of the device. The temperature measured has been used to calculate the heat generated inside the device by solving the heat conduction equation using a transverse matrix approach. It has been found by these calculations that about $97 \%-98 \%$ of the power supplied to the device are converted into the heat for un-encapsulated device and results in rapid degradation of device with time, which in turns leads to the increase in operating voltage and decrease in luminous intensity with operational time. Proper encapsulation has reduced the heat generated inside the device by about 3\%-4\%, thereby, increasing the life time of the device. However, the glass encapsulation reduces the possibilities of the device cooling by heat convection to the atmosphere and prohibited the maximum utilization of encapsulation. (C) 2014
\end{abstract} AIP Publishing LLC. [http://dx.doi.org/10.1063/1.4861412]

\section{INTRODUCTION}

Organic light emitting diodes (OLEDs) are very promising in technology due to their high efficiencies ${ }^{1-3}$ and low operating voltages. ${ }^{4,5}$ OLEDs have achieved maximum external quantum efficiencies $\left(\eta_{\text {ext }}\right)$ of nearly $45 \%$ (Ref. 6) and internal quantum efficiency $\left(\eta_{\text {int }}\right)$ nearly $100 \% .^{2,7,8}$ However, there is incredulity about their strong candidature in technology due to the lack of stability in organic molecular solids and degradation of OLEDs. ${ }^{9-13}$ Operational degradation of OLEDs, which is related to the loss of luminance efficiency, is due to the accumulation of non radiative centers (dark spots) and luminescence quenchers in emissive layers. ${ }^{14}$ The growth of the dark spot has been attributed to several mechanisms, such as crystallization of organic layers, ${ }^{9}$ electrochemical reactions at cathode/organic interfaces, ${ }^{10}$ migration of ionic species to enhance the rate of electrochemical reaction, ${ }^{11}$ the oxidation and delamination of cathode, etc. ${ }^{12}$ The dark spot primarily found to appear due to the presence of small particles at the time of fabrication. If their size is greater than the device thickness, then they can penetrate and migrate into aluminum cathode. Further, the device edges that are defined by the aluminum cathode also act as natural defect to the device fabrication. Schaer et al. ${ }^{14}$ studied growth

\footnotetext{
a) priyanka.tyagi.193@gmail.com

b) Author to whom correspondence should be addressed. E-mail address: ritu @nplindia.org. Tel. 91-11-45608596.
}

kinetics of dark spots under the water vapor and oxygen ambient. They observed a three order of magnitude higher growth rate in presence of water vapor as compared to oxygen ambience. Further, they observed that the other layers used in OLEDs may also cause this dark spot formation, such as lithium fluoride (LiF) used as an electron injection layer (EIL) has a hydrophilic nature, thereby, attracts water and facilitates it to aluminum cathode, where the ionic species act as an electrolyte in electrochemical reduction of water.

Theses dark spots act as the non radiative centers in active device and cause an increase in operating voltage and a decrease in luminescence intensity and homogeneity of the device. This provides an additional resistance which contributes to the Joule heating of the device. It has been reported that $97 \%-99 \%$ of the supplied power is dissipated via the heat losses inside an OLED. ${ }^{15}$ The internal Joule heating causes the exciton dissociation, which leads to the decrease in $\eta_{\text {ext }}$. Nakanotani et al. ${ }^{16}$ have studied the effect of the cathode diameter and the conductivity of substrate on device performance. They have correlated the decrease in $\eta_{\text {ext }}$ with the singlet-singlet annihilation (SSA) and singlet-heat annihilation (SHA). Joule heating can be correlated to the temperature rise of the device at the time of operation as it is not directly measurable. This surface temperature of OLED can be measured by different techniques, such as use of thermocouple, Raman spectroscopy, ${ }^{17,18}$ and infrared (IR)-thermography. ${ }^{19-21}$ IR-thermographic systems provide the images that represent the surface temperatures, or thermo grams, by measuring 
infrared radiation emanating from the surface of the object. IR imagers may resolve surface temperature differences of $0.1^{\circ} \mathrm{C}$ or less and have proved as a potential instrument to observe the surface temperature. ${ }^{19}$

The degradation of OLED can be reduced by avoiding the exposure of device with atmosphere. Glass encapsulation is generally performed to avoid the exposure of OLED with intruding species from outer atmosphere. This encapsulation diminishes the immerging of the reacting agents (water vapors and oxygen) in the device and consequently reduces the density of dark spots. However, the effect of encapsulation on the internal heating of the device remained a topic to be considered for detailed study. Recently, Forrest et al. ${ }^{15}$ have proposed a transmission matrix analysis for the thermal studies of OLEDs. They have solved the heat conduction equations by Laplace transform method proposed by Pipe ${ }^{22}$ to determine the synergy of thermal radiation, conduction, and convection and non-dissipative energy losses through OLED light emission. In their approach, they have included parallel and series pathways required for accurate consideration of losses by the combined processes of thermal convection, conduction, and radiation. Further, their method also include the heat generation within the layers caused by their internal resistances, losses through light emission, heat flow across interfaces between layers having resistances, and response to a thermal impulse. This makes their method to be applicable in most of the optoelectronic devices, which have multilayered structures and all these parameters must be included for an accurate analysis of heat losses.

In this work, we have measured the temperature of device by IR-thermography and studied the effect of internal Joule heating on the lifetime of the device. Further, we have estimated the heat losses inside the device by using transmission matrix analysis. In our study, we have evaluated the effect of internal Joule heating as well as intrusion by the outer atmosphere by thermal studies of encapsulated and unencapsulated OLEDs.

\section{EXPERIMENTAL}

OLEDs were fabricated on indium tin oxide (ITO) coated glass substrate having a sheet resistance of $20 \Omega / \square$, which were purchased for Vinkarola Inc. Substrates were then patterned and cleaned subsequently in de-ionized water, acetone, trichloroethylene, and propanol for 20 min each using an ultrasonic bath. Cleaned substrates were then dried in vacuum oven at $120^{\circ} \mathrm{C}$ for $30 \mathrm{~min}$ and then loaded into vacuum chamber. The device structure of OLEDs were ITO $(120 \mathrm{~nm}) / \alpha-\mathrm{NPD}$ $(35 \mathrm{~nm}) / \mathrm{Ir}(\mathrm{ppy})_{3}$ doped $\mathrm{CBP} \quad(30 \mathrm{~nm}) / \mathrm{BCP} \quad(6 \mathrm{~nm}) / \mathrm{Alq}_{3}$ $(28 \mathrm{~nm}) / \mathrm{LiF}(1 \mathrm{~nm}) / \mathrm{Al}(150 \mathrm{~nm})$. The layers were deposited at a base pressure of $4 \times 10^{-6}$ Torr. Organic layers were deposited at a rate of $0.4 \AA / \mathrm{s}$. Metal electrode was deposited at a rate of $5 \AA / s$. The rates of the host and guest were monitored in situ by using quartz crystal monitor for the deposition of doped layer and controlled by using a shutter. The size of each pixel was $4 \mathrm{~mm} \times 3 \mathrm{~mm}$. Thicknesses of the films were measured by quartz crystal monitor and confirmed by using ellipsometry. Current density-voltage-luminescence ( $\mathrm{J}-\mathrm{V}-\mathrm{L})$ characteristics were measured with a luminescence meter (LMT-1009) interfaced with a Kiethley 2400 programmable current voltage digital source meter. IR - thermographic measurements were carried out using an uncooled type IR camera VarioCAM hr with spectral range $7.5-14 \mu \mathrm{m}$. IR image video files were captured at $5 \mathrm{~Hz}$ frame rate for all the measurements. Optical images were captured using an optical microscope equipped with a CCD camera. All measurements were carried out at room temperature under ambient conditions.

\section{RESULTS AND DISCUSSIONS}

Figure 1 shows the schematic setup utilized for the temperature measurements of OLEDs using IR thermography. In this setup, OLEDs were placed on the focal point of an IR camera and then IR images were captured. These IR images represent the thermal radiations emitted by a surface and detection of these radiations depends on the thermal emissivity of the heated object. Thermal emissivity should be as close to unity for the proper IR wave's detection. Therefore, IR images were captured from the substrate side because the emissivity of glass is 0.9 , while the emissivity of aluminum is 0.02 . These images were captured with a constant current density applied to the device. Figure 2(a) shows the thermographic image of OLED at a current density of $40 \mathrm{~mA} / \mathrm{cm}^{2}$. IR imaging works on the principle of Wien's law $\left(\lambda_{\mathrm{m}} \mathrm{T}=\right.$ constant $)$ and relates the temperature of the emitting surface with the peak emission wavelength. The peak emission wavelength is sensitive to the temperature of the emitting surface. Therefore, these IR images were used to measure the temperature rise of the pixel with a constant current density applied to the device. Figure 2(a) also indicates the temperature rise of the device with the application of current density. It can be seen from this figure that the device temperature has increased with the increase in current density and this increase has been found to be from 1.6 to $9.8^{\circ} \mathrm{C}$ with the increase of current density from $10-40 \mathrm{~mA} / \mathrm{cm}^{2}$. Figure 2(b) shows the temperature profile of the pixel with time obtained by IR images at current density of 10, 20, 30, and $40 \mathrm{~mA} / \mathrm{cm}^{2}$. It can be seen from the figure that the temperature has increased very sharply soon after the application of current density to the device and then it started to stabilize and became almost constant after duration of $1 \mathrm{~min}$. This

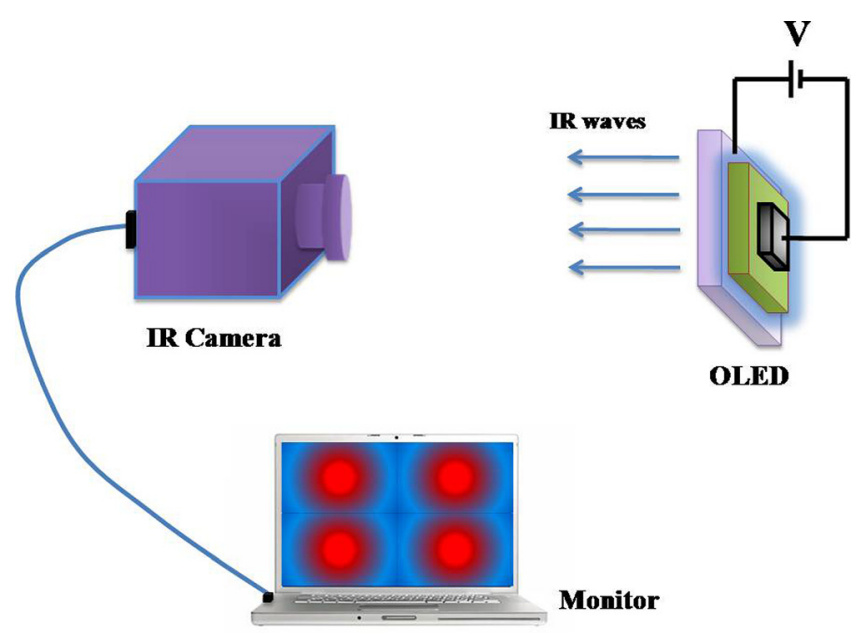

FIG. 1. Schematic setup used for temperature measurements of OLEDs using IR camera. 


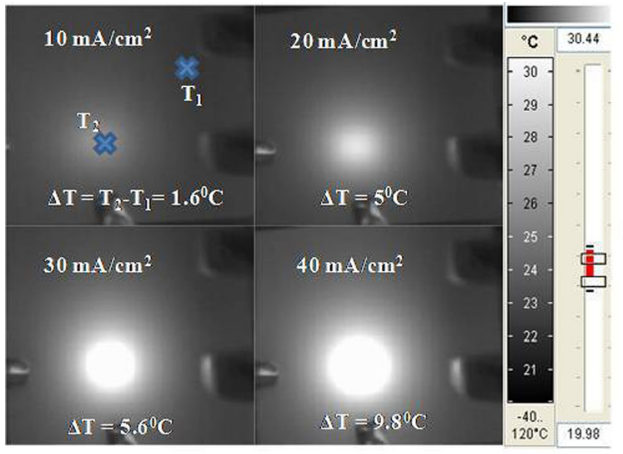

(a)

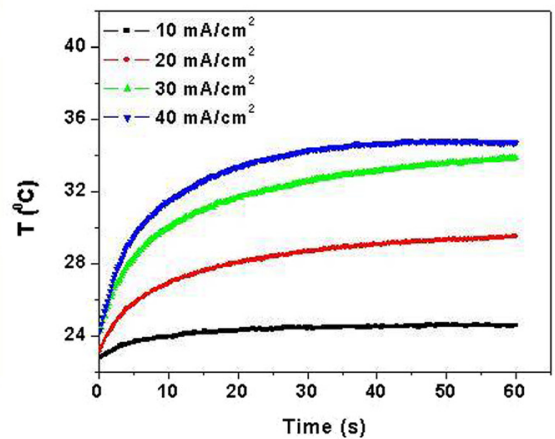

(b) duration has then been considered as the time required by the device to achieve the equilibrium with the surrounding and we have used this duration to estimate the temperature rise of the device.

In this study, we have fabricated two devices, one of which was encapsulated using a glass cover slip and UV curable epoxy and other was left un-encapsulated to study the effect of external contamination on the temperature rise inside the device. Temperature rise was measured for both devices at different temporal instance. Figure 3 shows the plot of temperature rise for un-encapsulated and encapsulated devices as a function of time at applied current densities of 10, 20, 30, 40, and $50 \mathrm{~mA} / \mathrm{cm}^{2}$. It can be seen from the Figure 3 that the temperature rise is more rapid for un-encapsulated device in comparison to the encapsulated device. The temperature rise has increased from $9.8^{\circ} \mathrm{C}$ to $16.6^{\circ} \mathrm{C}$ for un-encapsulated device within duration of $168 \mathrm{~h}$ at an applied current density of $40 \mathrm{~mA} / \mathrm{cm}^{2}$, while the corresponding value of increase for encapsulated device was $12.5^{\circ} \mathrm{C}$. Therefore, encapsulation has reduced the device temperature. Further, to quantify the temperature rise of the device, we have calculated the gradient of temperature rise per hour. Figure 4 shows this temperature rise per hour for both the devices as a function of current density. It can be seen from the figure that the gradient increase in temperature rise has an incremental pattern with current density for both the devices. However, encapsulated device has a slow increase of temperature in comparison to the

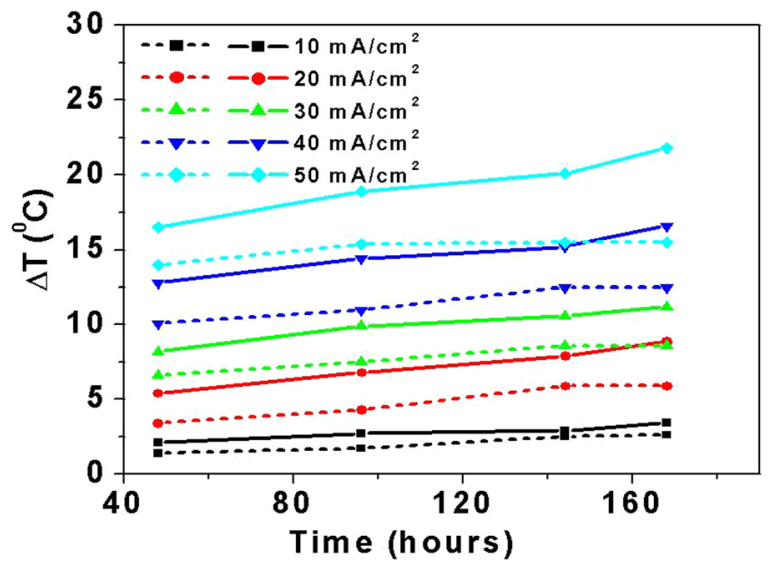

FIG. 3. Temperature rise of un-encapsulated (solid lines) and encapsulated (dashed lines) OLEDs as a function of time at current densities of 10, 20, 30, 40 , and $50 \mathrm{~mA} / \mathrm{cm}^{2}$. un-encapsulated device. Therefore, heat generated inside the device has stronger effect on the device temperature of un-encapsulated device in comparison to the encapsulated device.

The sources of heat generation inside an OLED are electrical losses at injection interfaces (cathode/ETL and anode/HTL), resistive losses inside the transport layers, nonradiative losses inside the emissive layer, and degradation of the device by moisture, oxygen, and dust particles. These losses contribute to the temperature rise of OLED. As current density has increased, pixel temperature has increased due to the increased heat generation inside OLED. It can also be seen from the figure that temperature rise has increased with the life time of OLEDs. Organic layers start degrading with time, thereby, deteriorating the injecting contacts, conductivity of transport layers. Therefore, the performance of OLEDs degrades with the life time, which results in a temperature rise of device. Encapsulation has restrained the moisture, oxygen, and dust particles from the device, thereby, abating the temperature rise.

Further, to get a complete understanding of the thermal processes, we have calculated the heat generation inside OLEDs using theoretical formalism introduced by Qi and Forrest ${ }^{15}$ based on transverse matrix approach for OLEDs. In this formalism, heat conduction equation was solved using Laplace transform method to study the combined effects of thermal radiation, conduction, and convection. There

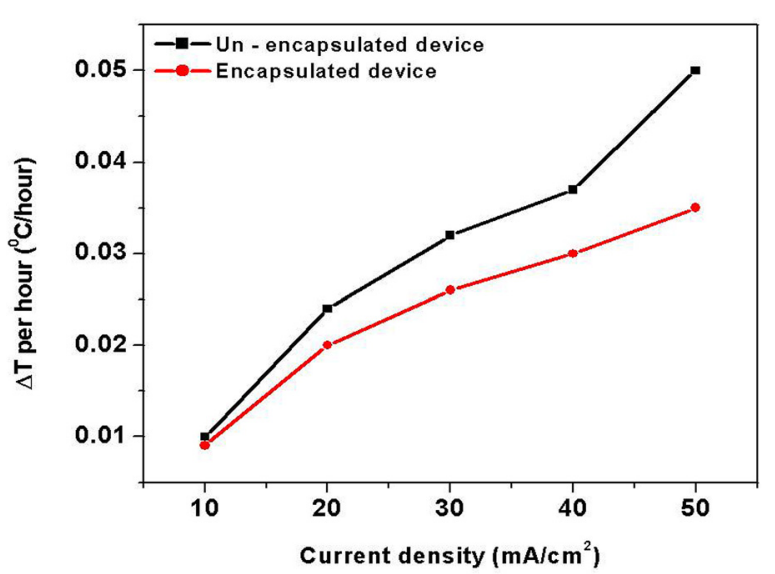

FIG. 4. Gradient increase in temperature rise per hour as a function of current density for encapsulated and un-encapsulated devices. 


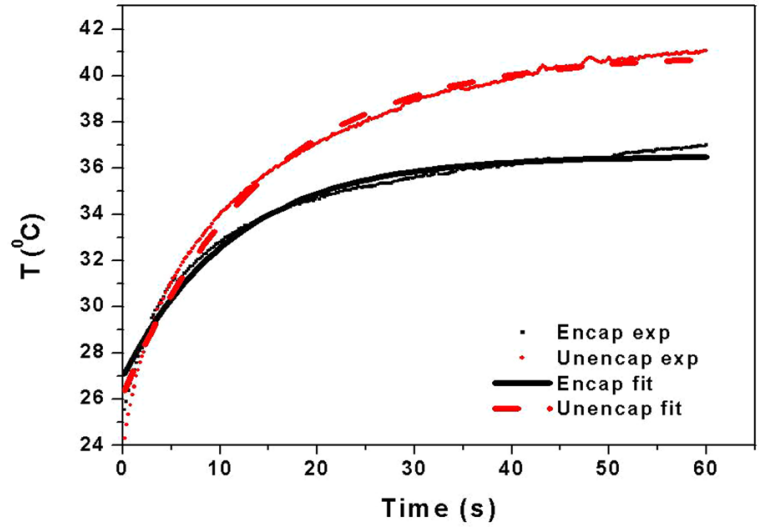

FIG. 5. Experimental and fitted (using transverse matrix approach) temperature data for un-encapsulated and encapsulated OLEDs.

approach also takes into account the dissipative energy losses through OLED light emission. According to their formalism, the source temperature can be correlated with the ambient temperature by the following equation: ${ }^{15}$

$$
\left[\begin{array}{c}
\hat{T}_{S R C} \\
\hat{Q}_{S R C}
\end{array}\right]=\left[M^{(L, R)}(\theta)\right]\left[\begin{array}{c}
\hat{T}_{0} \\
\hat{Q}_{0}^{L, R}
\end{array}\right],
$$

where $\hat{T}_{S R C}$ and $\hat{T}_{0}$ are Laplace transforms of the source and ambient temperatures, respectively, and $\hat{Q}_{S R C}, \hat{Q}_{L}$, and $\hat{Q}_{R}$ are Laplace transforms of heat flux of source, heat fluxes dissipated through substrate, and cathode side, respectively. In this equation, $\mathrm{M}^{\mathrm{L}}$ is composed of the conduction matrices for ITO anode, glass substrate, and air in sequence and $\mathrm{M}^{\mathrm{R}}$ is composed of the thermal conduction matrices for a single composed organic layer, metal cathode, and air in sequence. In our study, the ambient temperature has been considered as the room temperature and the heat flux of source has been varied. The conduction matrix is given as

$$
\left[T\left(\theta_{i}\right)\right]=\left[\begin{array}{cc}
\cosh \left(\theta_{i}\right) & Z_{i} \sinh \left(\theta_{i}\right) \\
\frac{\sinh \left(\theta_{i}\right)}{Z_{i}} & \cosh \left(\theta_{i}\right)
\end{array}\right],
$$

where $\theta_{i}=L_{i} \sqrt{C_{i} s / K_{i}}$ is the operational propagation coefficient characterized by $\mathrm{K}_{\mathrm{i}}$ (thermal conductivity), $\mathrm{C}_{\mathrm{i}}$ (volumetric heat capacity) and $\mathrm{L}_{\mathrm{i}}$ (thickness of the layer), and $Z_{i}=\sqrt{1 / K_{i} C_{i} S}$ is the characteristic thermal impedance of the layer. Figure 5 shows the fitting for temperature rise with operating time for un-encapsulated and encapsulated devices at a current density of $40 \mathrm{~mA} / \mathrm{cm}^{2}$. These data have been fitted using the parameters summarized in Table I. Heat

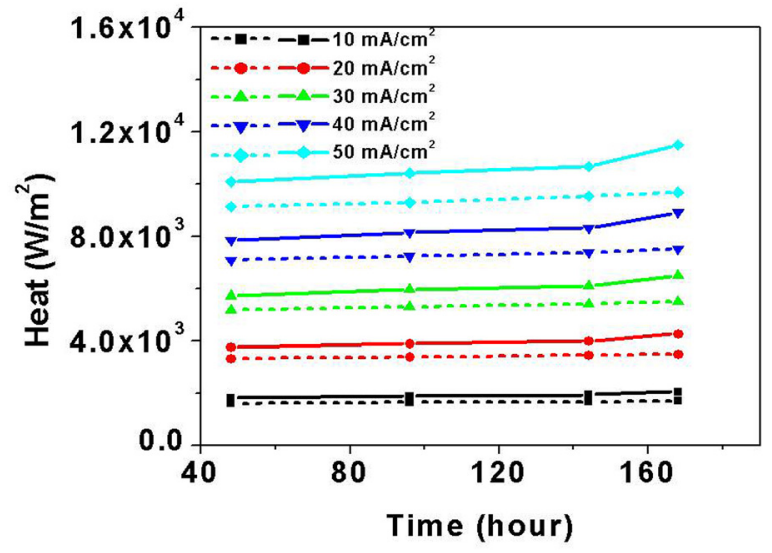

FIG. 6. Calculated heat generated inside the device for un-encapsulated (solid lines) and encapsulated (dashed lines) OLEDs as a function of time at current densities of $10,20,30,40$, and $50 \mathrm{~mA} / \mathrm{cm}^{2}$.

dissipation inside the device has been used as fitting parameter and the used values were 7600 and $6940 \mathrm{~W} / \mathrm{m}^{2}$, respectively, for un-encapsulated and encapsulated devices. The total power applied to the device is about 7750 and $7410 \mathrm{~W} / \mathrm{m}^{2}$ for un-encapsulated and encapsulated devices. Therefore, the losses as heat generated inside the device were about $98 \%$ and $94 \%$ in un-encapsulated and encapsulated devices, respectively. The similar values of heat losses were also observed by Qi and Forrest. ${ }^{15}$

We have obtained heat generated inside the unencapsulated and encapsulated OLEDs at different instance of time by fitting the experimental data for temperature measurements. Figure 6 shows the heat generated inside the device as a function of time for un-encapsulated and encapsulated devices, respectively, at current densities of 10, 20, 30, 40, and $50 \mathrm{~mA} / \mathrm{cm}^{2}$. It can be seen from the figure that the increase in current density has resulted in increased heat dissipation inside the device. The heat dissipation was found to increase with the increase in time which can be directly correlated to the degradation of device. It can be seen that the encapsulation of device has resulted in a slower increase in the heat generated inside the device by avoiding external exposure to moisture and oxygen from ambient, which degrades the organic layers. The losses in heat generated were found to be in the range of $97 \%-98 \%$ and $93 \%-94 \%$ to the total power in case of un-encapsulated and encapsulated devices, respectively. Therefore, the glass encapsulation has reduced the heat generated inside the device by about $3 \%-4 \%$.

In order to study the effect of heat dissipation inside the OLEDs on life time, we have measured the operating voltage

\begin{tabular}{|c|c|c|c|c|c|}
\hline Materials & Thickness $(\mu \mathrm{m})$ & Density $\left(\mathrm{Kg} / \mathrm{m}^{3}\right)$ & Heat capacity $(\mathrm{J} / \mathrm{KgK})$ & Thermal conductivity (W/Km) & Reference \\
\hline Air & - & 1.2 & $1.0 \times 10^{3}$ & $2.5 \times 10^{-2}$ & 23 and 24 \\
\hline Glass & 700 & $2.6 \times 10^{3}$ & $8.2 \times 10^{2}$ & 3.0 & 25 \\
\hline ITO & 0.12 & $7.2 \times 10^{3}$ & $3.4 \times 10^{2}$ & 8.0 & 26 \\
\hline Organic & 0.1 & $1.2 \times 10^{3}$ & $1.7 \times 10^{3}$ & 0.2 & 27 \\
\hline $\mathrm{Al}$ & 0.15 & $3.9 \times 10^{3}$ & $9.0 \times 10^{2}$ & 20 & 28 and 29 \\
\hline Encap & 700 & $2.6 \times 10^{3}$ & $8.2 \times 10^{2}$ & 3.0 & 23 and 24 \\
\hline
\end{tabular}

TABLE I. Materials constants used for the fitting of the experimentally measured temperature profile. 


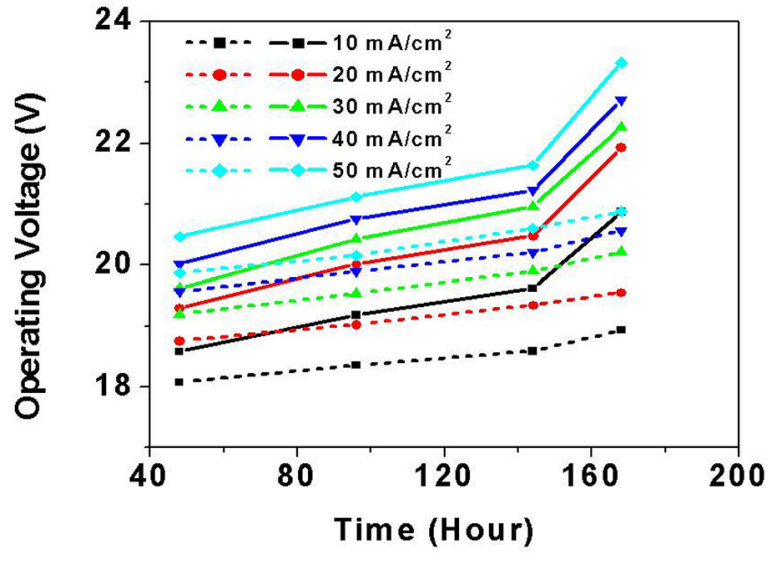

FIG. 7. Operating voltage of un-encapsulated (solid lines) and encapsulated (dashed lines) OLEDs as a function of time at current densities of 10, 20, 30, 40 , and $50 \mathrm{~mA} / \mathrm{cm}^{2}$.

and luminous intensity of OLEDs at the same temporal instances. Figure 7 shows the operating voltage as a function of time for un-encapsulated and encapsulated device at 10 , $20,30,40$, and $50 \mathrm{~mA} / \mathrm{cm}^{2}$ current density. It can be seen from the figures that un-encapsulated device have a faster increase of operating voltage than encapsulated device at the same value of current density. The operating voltage has increased from 19.38 to $22.71 \mathrm{~V}$ for un-encapsulated device within a duration of $168 \mathrm{~h}$ at an applied current density of $40 \mathrm{~mA} / \mathrm{cm}^{2}$, while the corresponding increase for encapsulated device were 18.54 to 20.08 V. Figure 8 shows the luminous intensity as a function of life time for both the devices. Luminous intensity has decreased for both the devices with time and this decrease is faster for un-encapsulated device. Further, we have captured optical images of both the OLEDs using an optical microscope at different instant of time.

Tables II and III summarizes the results of temperature and life time measurements for both un-encapsulated and encapsulated devices for all value of current densities. In this table, we have shown the increase in temperature rise, heat generated inside the device, operating voltages, and percentage decrease in luminescence. It can be seen from the table that encapsulation of the device slowed the rate of

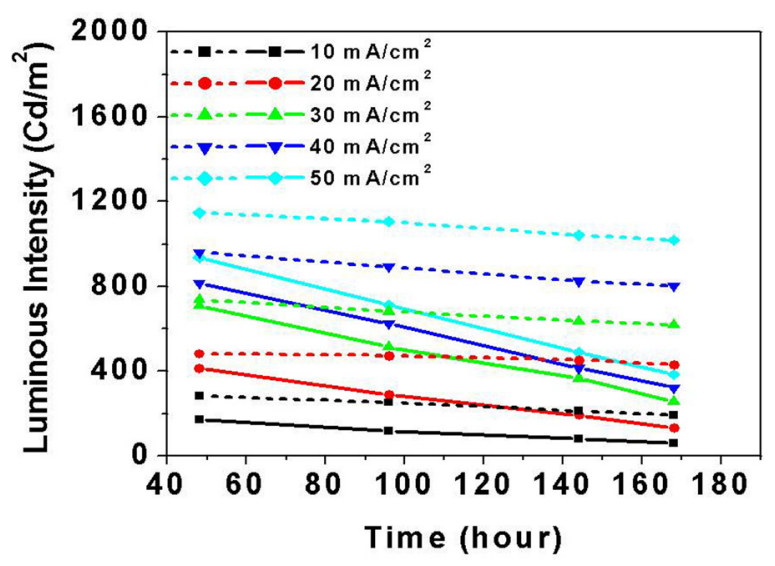

FIG. 8. Luminous intensity of un-encapsulated (solid lines) and encapsulated (dashed lines) OLEDs as a function of time at current densities of 10 , $20,30,40$, and $50 \mathrm{~mA} / \mathrm{cm}^{2}$.
TABLE II. Change in temperature rise, heat generated inside the device, operating voltage, and percentage decrease in luminous intensity within duration of $168 \mathrm{~h}$ for un-encapsulated device at current densities of $10,20,30$, 40 , and $50 \mathrm{~mA} / \mathrm{cm}^{2}$.

\begin{tabular}{lcccc}
\hline \hline & $\Delta \mathrm{T}\left({ }^{\circ} \mathrm{C}\right)$ & $\Delta \mathrm{H}\left(\mathrm{W} / \mathrm{m}^{2}\right)$ & $\Delta \mathrm{V}(\mathrm{V})$ & $\Delta \mathrm{L}(\%)$ \\
\hline $10 \mathrm{~mA} / \mathrm{cm}^{2}$ & 1.8 & 296 & 3.01 & 73 \\
$20 \mathrm{~mA} / \mathrm{cm}^{2}$ & 3.9 & 638 & 3.25 & 72 \\
$30 \mathrm{~mA} / \mathrm{cm}^{2}$ & 5.6 & 947 & 3.29 & 69 \\
$40 \mathrm{~mA} / \mathrm{cm}^{2}$ & 6.8 & 1306 & 3.33 & 65 \\
$50 \mathrm{~mA} / \mathrm{cm}^{2}$ & 9.1 & 1793 & 3.64 & 63 \\
\hline \hline
\end{tabular}

degradation of the device. As a result, the change in temperature rise has decreased from $1.8,3.9,5.6,6.8$, and $9.1^{\circ} \mathrm{C}$ to $1.5,3.3,5.3,6.1$, and $6.7^{\circ} \mathrm{C}$ for current densities of 10,20 , 30,40 , and $50 \mathrm{~mA} / \mathrm{cm}^{2}$, respectively, within $168 \mathrm{~h}$. Similarly, the heat generated inside the device has also decreased from $296,638,947,1306$, and $1793 \mathrm{~W} / \mathrm{m}^{2}$ to 126 , $221,403,576$, and $781 \mathrm{~W} / \mathrm{m}^{2}$ for current densities of 10,20 , 30,40 , and $50 \mathrm{~mA} / \mathrm{cm}^{2}$ within $168 \mathrm{~h}$. This has resulted in a better stability of the device in terms of operating voltages and luminous intensities. The operating voltage has increased by only $1.32-1.65 \mathrm{~V}$ for all current density values and luminous intensity has decreased by about $31 \%-38 \%$.

Figure 9 illustrates schematically the different sources of degradation of OLED. These sources of degradation can be divided into two subgroups of external and internal degradation sources. The external degradation sources are oxygen, moisture, and dust particles, which intrude the device and cause the deterioration of the organic layers and metal cathode and in process creates non-radiative centers. These nonradiative centers become a source of heat generation inside the device. The other degradation sources, i.e., internal degradation sources are the electrical and non-radiative losses caused by the organic layers. The sources of these losses include the interface barrier at injecting contacts, high resistance of organic transport layers, and non-radiative decays inside the emissive layer. Therefore, the total heat generated inside the device is combined due to these two sources. Encapsulation of device protects the device from external intrusion by oxygen, moisture, and dust particles, thereby, reducing the heat generated inside the device. However, it cannot prevent the device from the internally generated heat and caused a temperature rise of the device. At the same time, encapsulating the device with glass impedes the convective cooling of the device from the atmosphere due to the

TABLE III. Change in temperature rise, heat generated inside the device, operating voltage, and percentage decrease in luminous intensity within duration of $168 \mathrm{~h}$ for encapsulated device at current densities of 10, 20, 30, 40, and $50 \mathrm{~mA} / \mathrm{cm}^{2}$.

\begin{tabular}{lcccc}
\hline \hline & $\Delta \mathrm{T}\left({ }^{\circ} \mathrm{C}\right)$ & $\Delta \mathrm{H}\left(\mathrm{W} / \mathrm{m}^{2}\right)$ & $\Delta \mathrm{V}(\mathrm{V})$ & $\Delta \mathrm{L}(\%)$ \\
\hline $10 \mathrm{~mA} / \mathrm{cm}^{2}$ & 1.5 & 126 & 1.32 & 38 \\
$20 \mathrm{~mA} / \mathrm{cm}^{2}$ & 3.3 & 221 & 1.2 & 36 \\
$30 \mathrm{~mA} / \mathrm{cm}^{2}$ & 5.3 & 403 & 1.44 & 36 \\
$40 \mathrm{~mA} / \mathrm{cm}^{2}$ & 6.1 & 576 & 1.54 & 34 \\
$50 \mathrm{~mA} / \mathrm{cm}^{2}$ & 6.7 & 781 & 1.65 & 31 \\
\hline
\end{tabular}




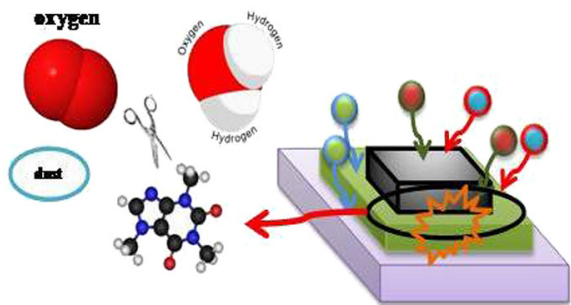

$\sum_{2 m}^{M} \rightarrow$ Representation of Heat

(a)

low thermal conductivity of glass. Due to the encapsulation, the device has glass on both sides, which a poor conductor of heat, therefore, encapsulated device still has a significant amount of heat generated inside the device. However, in totality, encapsulation leads to the decrease in heat generation, thereby, increasing the life time of OLED..$^{9-14,30}$

\section{CONCLUSIONS}

Temporal temperature measurements of OLEDs operating at different current densities were performed using IRthermography. The temperature data have been utilized to quantify the heat generated inside the device as a function of time and an incremental pattern of heat generation was observed with time. The temperature measurements have been correlated with the life time of OLEDs by measuring the operating voltage and luminous intensity of the devices. These data have been compared for un-encapsulated and encapsulated devices.

\section{ACKNOWLEDGMENTS}

The authors gratefully recognize the financial support from the Project NWP-55 (TAPSUN). One of the authors (PT) acknowledges Council of Scientific and Industrial Research for providing the Senior Research Fellowship.

${ }^{1}$ C. W. Tang and S. A. Van Slyke, Appl. Phys. Lett. 51, 913 (1987).

${ }^{2}$ J. H. Burroughes, D. D. C. Bradley, A. R. Brown, R. N. Marks, K. Mackay,

R. H. Friend, P. L. Burn, and A. B. Holmes, Nature 347, 539 (1990).

${ }^{3}$ B. C. Krummacher, V. E. Choong, M. K. Mathai, S. A. Choulis, and F. So, Appl. Phys. Lett. 88, 113506 (2006).

${ }^{4}$ P. Tyagi, R. Srivastava, A. Kumar, G. Chauhan, A. Kumar, S. S. Bawa, and M. N. Kamalasanan, Syn. Met. 160, 1126 (2010). (b)

${ }^{5}$ K. Walzer, B. Maennig, M. Pfeiffer, and K. Leo, Chem. Rev. 107, 1233 (2007).

${ }^{6}$ S. Reineke, F. Lindner, G. Schwartz, N. Seidler, K. Walzer, B. Lüssem, and K. Leo, Nature 459, 234 (2009).

${ }^{7}$ C. Adachi, M. A. Baldo, M. E. Thompson, and S. R. Forrest, J. Appl. Phys. 90, 5048 (2001).

${ }^{8}$ A. Kumar, R. Srivastava, D. S. Mehta, and M. N. Kamalasanan, Org. Electr. 13, 1750 (2012).

${ }^{9}$ H. Aziz, Z. Popovic, S. Xie, A.-M. Hor, N.-X. Hu, C. Tripp, and G. Xu, Appl. Phys. Lett. 72, 756 (1998).

${ }^{10}$ L. M. Do, M. Oyamada, A. Koike, E. M. Han, N. Yamamoto, and M. Fujihira, Thin Solid Films 273, 209 (1996).

${ }^{11}$ E. Gautier, A. Lorin, J. M. Nunzi, A. Schalchli, J. J. Benattar, and D. Vital, Appl. Phys. Lett. 69, 1071 (1996).

${ }^{12}$ H. Aziz, Z. D. Popovic, N. X. Hu, A. M. Hor, and G. Xu, Science 283, $1900(1999)$

${ }^{13}$ L. M. Do, E. Han, Y. Niidome, M. Fujihira, T. Kanno, S. Yoshida, A. Maeda, and A. J. Ikushima, J. Appl. Phys. 76, 5118 (1994).

${ }^{14}$ M. Schaer, F. Nüesch, D. Berner, W. Leo, and L. Zuppiroli, Adv. Funct. Mat. 11, 116 (2001).

${ }^{15}$ X. Qi and S. R. Forrest, J. Appl. Phys. 110, 124516 (2011).

${ }^{16}$ H. Nakanotani, H. Sasabe, and C. Adachi, Appl. Phys. Lett. 86, 213506 (2005).

${ }^{17}$ H. Tsuji and Y. Furukawa, Chem. Phys. Lett. 488, 206 (2010).

${ }^{18}$ T. Sugiyama, H. Tsuji, and Y. Furukawa, Chem. Phys. Lett. 453, 238 (2008).

${ }^{19} \mathrm{~B}$. Grifith, D. Turler, and H. Goudey, Imaging Science and Technology (John Wiley and sons, 2001).

${ }^{20}$ J. Park, H. Ham, and C. Park, Org. Electr. 12, 227 (2011).

${ }^{21}$ S. Chung, J.-H. Lee, J. Jeong, J.-J. Kim, and Y. Hong, Appl. Phys. Lett. 94, 253302 (2009).

${ }^{22}$ L. A. Pipes, J. Franklin Inst. 263, 195 (1957).

${ }^{23}$ I. Hatta, Rev. Sci. Instrum. 50, 292 (1979).

${ }^{24}$ E. Lemmon and R. Jacobsen, Int. J. Thermophys. 25, 21 (2004).

${ }^{25}$ W. H. Tanttila, Phys. Rev. Lett. 39, 554 (1977).

${ }^{26}$ T. Yagi, K. Tamano, Y. Sato, N. Taketoshi, T. Baba, and Y. Shigesato, J. Vac. Sci. Technol. A 23, 1180 (2005).

${ }^{27}$ H. Lee, Rev. Sci. Instrum. 53, 884 (1982).

${ }^{28}$ T. E. Pochapsky, Acta Metall. 1, 747 (1953).

${ }^{29}$ A. Woodcraft, Cryogenics 45, 626 (2005).

${ }^{30} \mathrm{P}$. Tyagi, A. Kumar, L. I. Giri, M. K. Palai, S. Tuli, M. N. Kamalasanan, and R. Srivastava, Opt. Lett. 38, 3854 (2013). 